Check for updates

Kent, UK

Cite this as: $B M J 2021 ; 374: n 2296$ http://dx.doi.org/10.1136/bmj.n2296 Published: 17 September 2021

\title{
Covid-19: Migrants face barriers accessing healthcare during the pandemic, report shows
}

\section{Jacqui Wise}

The covid-19 pandemic exacerbated existing inequalities for refugees, asylum seekers, and migrants, who reported higher levels of bad health and inadequate housing as well as difficulties accessing health services, a report from the University of Birmingham has shown. ${ }^{1}$

The report analysed data from 750 migrants who accessed services run by Doctors of the World-a non-governmental organisation that runs clinics and provides support to excluded people. It found that the number of average consultations per month dropped from 178 in January 2020 to 58 in September 2020 at one of the peaks of the pandemic. The drop is most likely because of the move to telephone consultations. At the same time there was a significant increase in the number of service users reporting "bad" or "very bad" health.

The number of people who reported insecure or inadequate housing situations rose from $44 \%$ to $62.8 \%$ during the pandemic. However, the number of people reporting as homeless dropped slightly from $6.3 \%$ to $6.1 \%$. In March 2020 the government launched the "Everyone in" policy to provide hotel and emergency accommodation to all people sleeping on the streets regardless of immigration status in response to the covid-19 crisis.

The report, which was funded by the Nuffield Foundation and the Economic and Research Council, found a greater number of service users had some form of health coverage but still found it difficult to access care. Most consultation requests were around help with GP registration and queries about charging.

People with insecure immigration status are often not registered with a GP and are largely excluded from NHS services. This has implications for the covid-19 vaccination programme which requires people to have an NHS number and an active GP registration in order to book a vaccination appointment, the report pointed out.

It made several recommendations including ensuring that all migrants, asylum seekers, and refugees can access the healthcare services they are entitled to, especially GP registration. It also called for face-to-face provision of services to be available and for provision of wifi or data to be a priority for people living in poverty so they are not excluded from services as they move online.

Jenny Phillimore, professor of migration and superdiversity at the University of Birmingham, said, "Our analysis clearly indicates that the shift from face-to-face to virtual or phone services risks excluding the most vulnerable migrants."
Anna Miller, head of policy and advocacy at Doctors of the World, said, "Unable to access NHS services, forced to manage health conditions alone, and struggling with poor housing, the report shows just how difficult the pandemic has been for people with insecure immigration status." She added, "The importance of this cannot be understated-our pandemic response relies on the whole population having good access to medical care and being able to protect themselves from the virus."

1 Lessard-Phillips L, Fu L, Lindenmeyer A, Phillimore J. Migration and vulnerability during the pandemic: barriers to wellbeing. Institute for Research into Superdiversity. September 2021. www.doctorsoftheworld.org.uk/wp-content/uploads/2021/09/Barriers-to-wellbeing-09.21.pdf.

This article is made freely available for use in accordance with BMJ's website terms and conditions for the duration of the covid-19 pandemic or until otherwise determined by BMJ. You may use, download and print the article for any lawful, non-commercial purpose (including text and data mining) provided that all copyright notices and trade marks are retained. 